\title{
Near future climate change projections with implications for the agricultural sector of three major Mediterranean islands
}

\author{
Konstantinos V. Varotsos ${ }^{1}$ (D) Anna Karali ${ }^{1} \cdot$ Giannis Lemesios $^{1} \cdot$ Gianna Kitsara $^{1} \cdot$ Marco Moriondo $^{2} \cdot$ Camilla Dibari $^{3}$. \\ Luisa Leolini $^{3} \cdot$ Christos Giannakopoulos $^{1}$
}

Received: 30 March 2020 / Accepted: 5 December 2020 / Published online: 30 January 2021

(C) The Author(s) 2020

\begin{abstract}
The paper presents the analysis of a sub-set of high-resolution bias-adjusted simulations from the EURO-CORDEX initiative, in order to examine the changes in the mean climate and the extremes in three Mediterranean islands, namely, Sicily, Crete and Cyprus, in the near future (2031-2060) compared to the present climate (1971-2000), under two future scenarios, i.e. RCP4.5 and RCP8.5. The analysis entails commonly used climatic indices of interest related to the islands' agricultural sector. The results indicate robust increases for both the mean maximum and minimum temperatures on a seasonal basis, as well as for the temperature related extremes under both climate scenarios. On the contrary, the changes in precipitation are less pronounced as the changes in the seasonal precipitation are not found statistically significant for the three islands under both scenarios. The projected warming combined with the projected unchanged precipitation pattern in the future, especially in spring and summer, might expose the crops to conditions with a negative impact on the plants' phenology, leading to implications on crop production and quality. The results presented here might be the basis for the development of an adaptation strategy specifically targeted on the three islands but also replicable to other Mediterranean islands.
\end{abstract}

Keywords Climate change $\cdot$ Bias-adjusted climate simulations $\cdot$ Mediterranean islands $\cdot$ Agricultural sector $\cdot$ Uncertainties Climate indicators

\section{Introduction}

The Mediterranean area is considered one of the "Hot Spots for Climate Change", meaning that the climate in the area is especially susceptible to climate change (Giorgi 2006).
Hence, in the past 15 years, it has been the target of a significant amount of studies examining the impacts of climate change with the major findings indicating that the future warming in the area will be higher than the global mean by $25 \%$ and $40 \%$ in the annual and the seasonal timescales

\begin{tabular}{l}
\hline Communicated by Wolfgang Cramer \\
\hline $\begin{array}{l}\text { Konstantinos V. Varotsos } \\
\text { varotsos@noa.gr }\end{array}$ \\
Anna Karali \\
akarali@noa.gr \\
Giannis Lemesios \\
jlemesios@noa.gr \\
Gianna Kitsara \\
gkitsara@noa.gr \\
Marco Moriondo \\
marco.moriondo@cnr.it \\
Camilla Dibari \\
camilla.dibari@unifi.it
\end{tabular}

\author{
Luisa Leolini \\ luisa.leolini@unifi.it \\ Christos Giannakopoulos \\ cgiannak@noa.gr \\ 1 Institute for Environmental Research \& Sustainable Development, \\ National Observatory of Athens, I. Metaxa \& Vas. Pavlou, \\ GR-15236 Palea, Penteli, Greece \\ 2 National Research Council of Italy, Institute of BioEconomy \\ (CNR-IBE), 500019, Florence, Italy \\ 3 Department of Agriculture, Food, Environment and Forestry \\ (DAGRI), University of Florence, Piazzale delle Cascine 18, \\ 50144 Firenze, Italy
}


(mostly summer), respectively (e.g. Lionello and Scarascia 2018). In addition, this warming is expected to be associated with an increase of high-temperature and heatwave events, reduced total precipitation but increased extreme precipitation events, with the actual magnitude of the changes varying depending on the particular region across the Mediterranean, as well as the regional climate modelling experiments conducted (Cramer et al. 2018 and references therein). These changes may adversely affect public health as well as vital economic sectors, such as agriculture and tourism, which provide food, services and resources, and guarantee the livelihood of the communities in the area.

The most recent studies on the climate change impacts in the Mediterranean area using the latest state-of-the- art modelling experiments from the EURO-CORDEX initiative examine the impacts on the wider European and/or Mediterranean domain (e.g. Vautard et al. 2013; Jacob et al. 2014; Dosio 2016; Dosio and Fischer 2018; Zittis et al. 2019). However, in these studies, an overall picture of the impacts over the Mediterranean area can be found, while the localized climatological information needed to enable climate change impact studies and develop adaptation strategies on a national or regional level is very difficult to be extracted.

In this study, we examine the change in the mean and extreme climate in the near future focusing over three Mediterranean islands, i.e. Sicily, Crete and Cyprus, using an ensemble of high-resolution, bias-adjusted regional climate model (RCM) simulations from EURO-CORDEX. Previous studies analysing observational data have shown that the three islands are already experiencing changes in climate. In particular, Kostopoulou and Jones (2005) analysing observational data during the period 1958-2000 over the Eastern Mediterranean found statistically significant positive trends for both the minimum and maximum summer temperatures as well for an index related to heatwave duration over Sicily and Crete. The warming over Sicily and Crete identified by Kostopoulou and Jones (2005) was also verified by the recent studies of Viola et al. (2014) and Founda et al. (2019), respectively. In particular, Viola et al. (2014) attributed the statistical significant temperature trend over Sicily during the period 1924-2006 to the rise of temperatures in the last years of the past century, while Founda et al. (2019) post-processing observational data from Crete and Cyprus for the last 60 years found a significant lengthening in the period of hot extremes with the more significant changes related to the extremes associated with minimum temperatures. Regarding precipitation, Cannarozzo et al. (2006) examining precipitation trends on an annual and seasonal basis from 247 stations in Sicily during the period 1921-2000 found a statistically significant negative trend in the western and southwestern part of the island with the trend however not being statistically significant over the period 1961-1990. Philandras et al. (2011) based on observations from 40 stations in the
Mediterranean area found no statistically significant trends for both the annual total precipitation and the annual number of rain days for locations in Sicily during the period 1965 2010 and in Crete and Cyprus during the period 1951-2010. In addition, Varouchakis et al. (2018) used data from 52 weather stations in Crete for the period 1981-2014 and suggested that the annual rainfall remained stable for the period examined.

Although a number of studies have assessed the climate change impacts in the area covering the three islands (e.g. Zanis et al. 2009; Giannakopoulos et al. 2011; Hadjinicolaou et al. 2011; Kostopoulou et al. 2014; Zittis et al. 2016), these studies have been conducted using RCMs with a horizontal resolution of about $25 \mathrm{~km}$ with the future period simulations driven by the previous SRES emission scenarios. It should be mentioned that recently Zittis et al. (2020) performing simulations with the WRF model, optimized over Cyprus, found trends towards a drier and warmer climatic regime with the most prominent changes evident by the end of the twenty-first century under the new representative concentration pathway scenario 8.5 (RCP8.5). To our knowledge, this is the first study quantifying the climate change impacts over the three islands using a high-resolution multi-model bias-adjusted ensemble approach. In addition, it should be noted that this study is related to the LIFE-ADAPT2CLIMA project (LIFE14 CCA/GR/ 000928) in which the main goal is to increase knowledge on the vulnerability of the Mediterranean agricultural sector to climate change and to support decision-making for adaptation planning. Therefore, the results presented in the current study are discussed for the specific sector.

\section{Data and methods}

We employ daily maximum (TX) and daily minimum temperatures (TN), as well as daily precipitation (RR) for the three islands of interest from a sub-ensemble of five RCMs (Table S1) from the EURO-CORDEX modelling experiment (http://www.euro-cordex.net) with the model sub-ensemble used in this study being similar to the five-member sub-ensemble identified and proposed in Bartók et al. (2019). The horizontal resolution of the models is $0.11^{\circ}$, while the simulated data in this study cover two periods: the 1971-2000 which is used as the reference period and the period 20312060 under two representative concentration pathway (RCP) scenarios, the RCP4.5 and RCP8.5 (Moss et al. 2010; van Vuuren et al. 2011). The future period has been chosen specifically for the needs of the stakeholders and policy-makers involved in the project to assist them in long-term adaptation planning.

It should be noted that the evaluation analysis regarding the models performance against E-OBSv20 (horizontal resolution $0.1^{\circ}$, Cornes et al. 2018) during the period 1971-2000 
revealed, depending on the island and the model, both cold and warm, as well as dry and wet, biases for the examined temperatures and precipitation, respectively. In particular, the models seem to capture quite well the mean gridded observational seasonal pattern of the daily TX and TN and to a lesser extent that of RR on each island (Fig. S1). The root mean square error (RMSE) and the mean absolute error (MAE) for TX are in the range of 1.2 to $3.4^{\circ} \mathrm{C}$ and 1.1 to $3.4^{\circ} \mathrm{C}$, respectively, while lower values are shown for $\mathrm{TN}$ of about $0.3-$ $3.7^{\circ} \mathrm{C}$ for both the statistical measures. For RR the normalized mean square error (NRMSE) ranges from about 10 to $50 \%$ with the highest deviations shown for Crete. Therefore, we opted to perform bias adjustment to each model's "raw" output based on E-OBSv20 using the empirical quantile mapping (EQM) method (Iturbide et al. 2019; Casanueva et al. 2020a, b). More specifically, EQM works by matching the simulated and observed empirical cumulative distributions by establishing a quantile-dependent correction function between them during the reference period. The calibration is carried out independently for each model and each day of the year with a moving window of 91 days, considering the full period 19712000 , for each one of the grid points covering the three islands. The correction functions are then applied to the historical period (1971-2000) and the future period (20312060). For more details on the EQM method and its implementation, the reader is referred to the studies of Iturbide et al. (2019) and Casanueva et al. (2020a, b). It is noted that prior to bias adjustment, the RCM's daily output for the examined variables are remapped on the E-OBS grid by choosing the closet grid point to the grid points of E-OBS on each one of the islands (Fig 1).

To examine the changes in the mean climate and in the extremes over the three islands, a number of absolute and threshold indices (Table S2) on a seasonal basis (winter (DJF), spring (MAM), summer (JJA), autumn (SON)) are analysed. The indices presented in this study are a selection of indices from the Expert Team on Climate Change
Detection and Indices (ETCCDI) (Zhang et al. 2011), as well as indices defined by the technical committee and then modified by the experts of the three steering committees of the ADAPT2CLIMA project. The majority of the indices selected are related to the different phenological stages of the plant, crop production and quality for the most important cultivations (in terms of total revenues) in the islands, namely, potatoes, tomatoes, olives, grapes, wheat and barley (http:// adapt2clima.eu/uploads/2017/ADAPT2CLIMA_DEL_C.3 Final_3.pdf).

For each of the indices, in each (land) grid point over the three islands, the change between the future and the reference period is considered robust, when the changes in at least three out of five models are found statistically significant and when the change in the same models is of the same sign. The first criterion is examined by using the 95th percentile confidence intervals as derived by bootstrap (Giannakopoulos et al. 2011; Varotsos et al. 2019). If only one of the criteria is met, the change at the specific grid point is not considered significant.

\section{Results and discussion}

\section{Present climate simulations}

In Fig. 2 the results of the ensemble mean for the daily maximum temperatures (TX) averaged over the period 1971-2000 are shown. From the figure, it is evident that Sicily and Crete exhibit similar mean values (over the grid points covering the two islands) for all seasons, ranging from about $12.5^{\circ} \mathrm{C}$ in DJF to about $27^{\circ} \mathrm{C}$ in JJA, while for Cyprus the mean values are about $4-4.5{ }^{\circ} \mathrm{C}$ higher per season. In all seasons, the highest temperatures for Sicily are shown for the eastern, southern and western near the coast areas, for Crete in the northwestern, northeastern and southern areas, while for Cyprus in the central and northeastern areas. The lowest values over the three islands are shown for the mountainous

\section{E-OBS elevation}
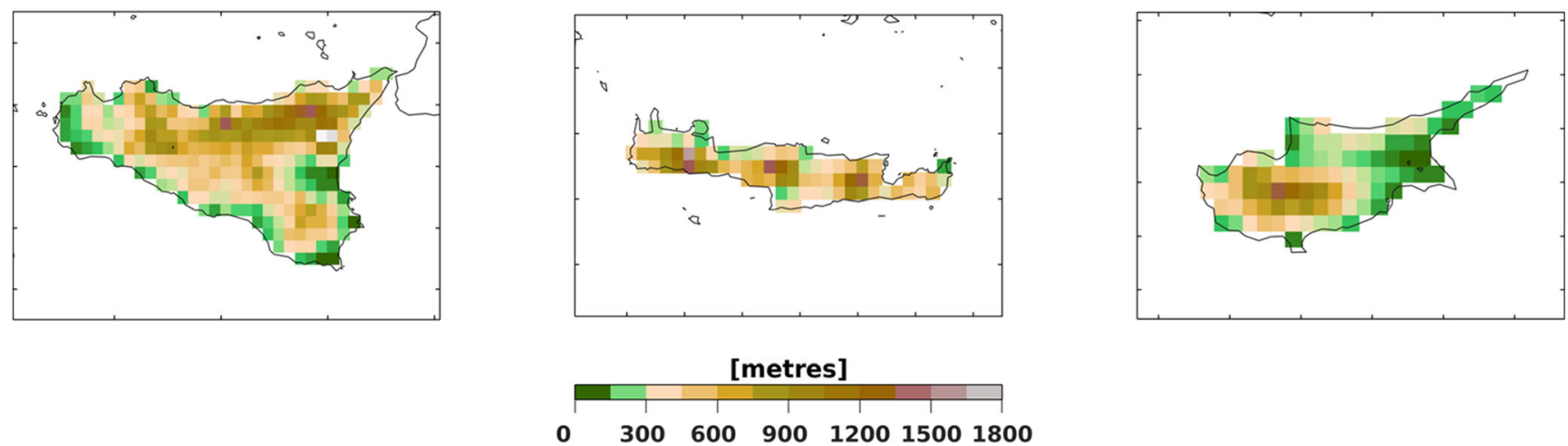

Fig. 1 E-OBS elevation over Sicily (left panel), Crete (middle panel) and Cyprus (right panel). The number of land grid points covering the islands is 258 for Sicily, 77 for Crete and 88 for Cyprus 
TX [DJF 1971-2000]
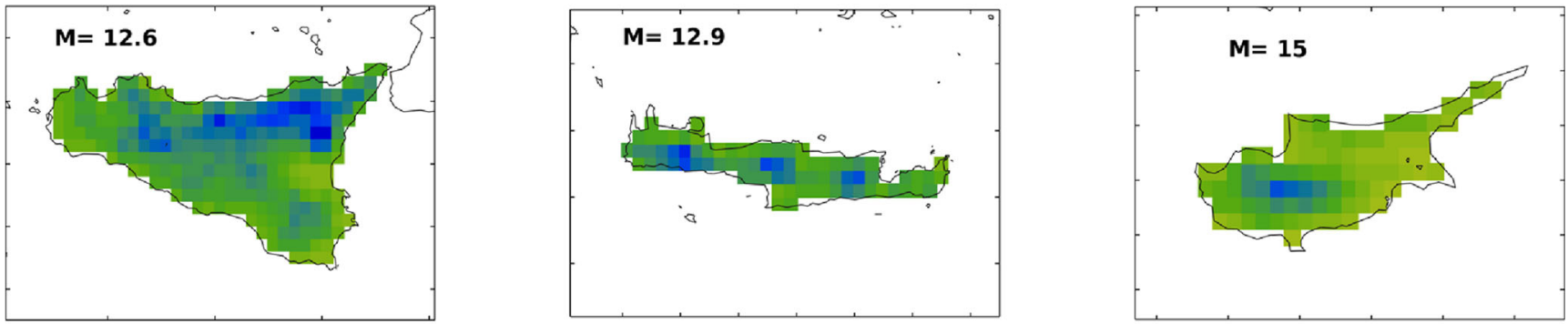

\section{TX [MAM 1971-2000]}
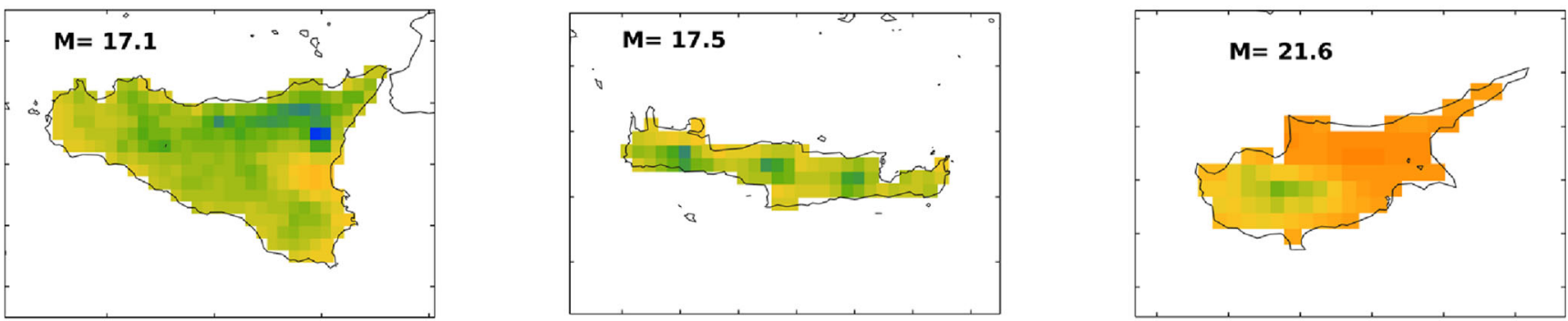

\section{TX [JJA 1971-2000]}
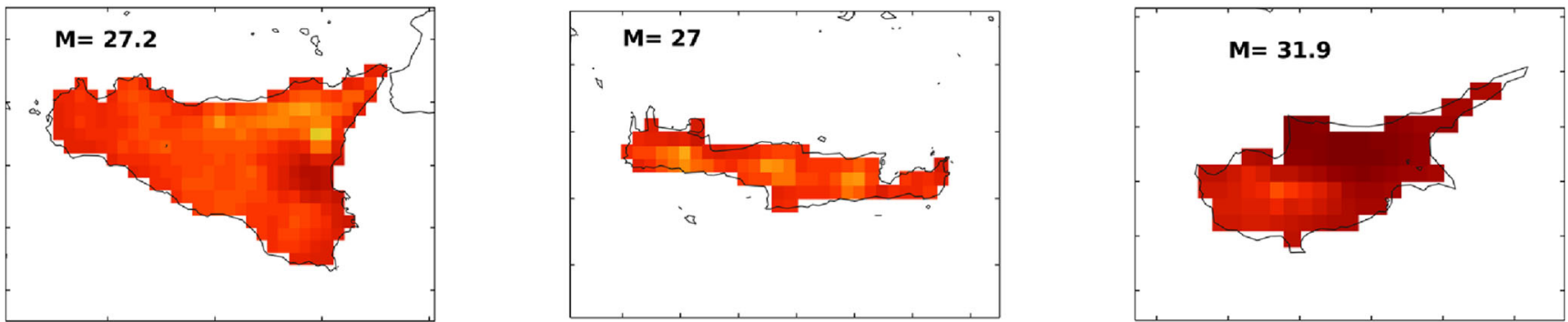

\section{TX [SON 1971-2000]}
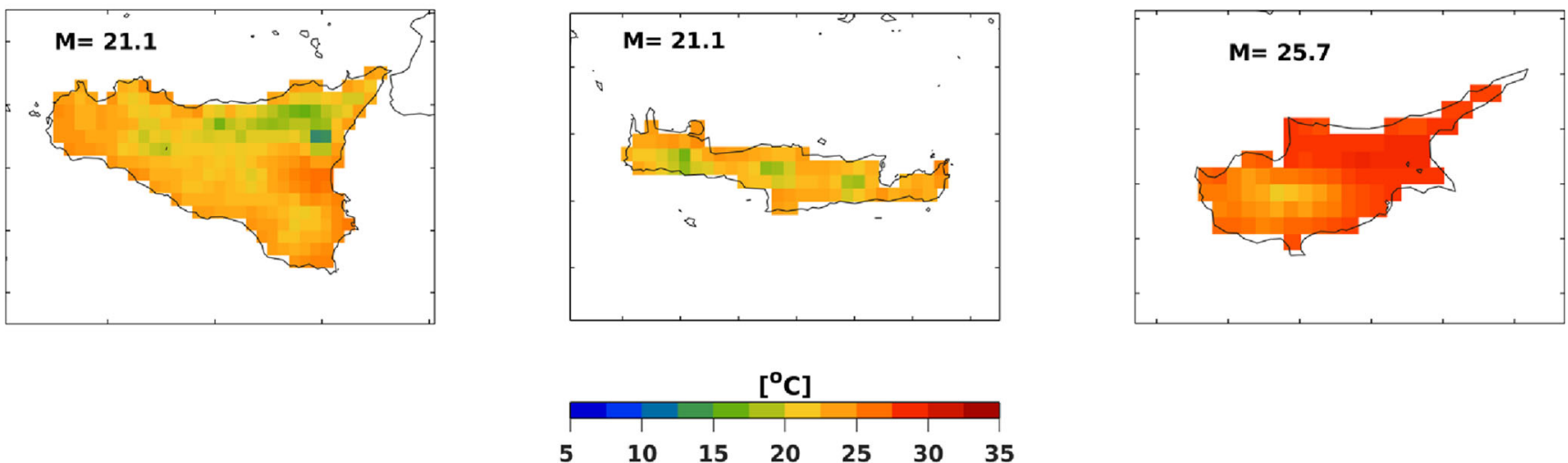

Fig. 2 Mean seasonal daily maximum temperatures (TX) for the five-member model sub-ensemble and the period 1971-2000. In each panel, M denotes the spatial average over the grid points covering each island. Units are the same as in the colourbar

areas. As far as the number of days with daily maximum temperatures higher than $25{ }^{\circ} \mathrm{C}$ (SU, Fig. S2) is concerned, in Sicily and Crete, the highest average number of days ( 70 days/season) is calculated for JJA, with many areas presenting even higher numbers ( $~ 90$ days). In MAM and SON, about 5 and 22 days/season are calculated on average, respectively, for both islands with the highest values reaching about 16 days/year in MAM and about 35-40 days/year in SON. For Cyprus, the averaged SU values are higher for all seasons reaching 25, 90 and 52 days/season for MAM, JJA and SON, respectively. The highest number of hot days (days with daily maximum temperatures $>30{ }^{\circ} \mathrm{C}, \mathrm{HD}$, Fig. S3) is 
calculated for JJA over the three islands with the average number of days/season being about 18, 14 and 67 for Sicily, Crete and Cyprus, respectively. Nevertheless, the highest values reach about $45-55$ days/season in the eastern near coastal areas of Sicily, 35-45 days/season in the northwestern and northeastern areas of Crete, while for Cyprus the central, northern and northeastern areas experience hot days during the whole summer season. In MAM the three islands exhibit much lower values for the specific index with the maximum values simulated for Sicily and Crete being lower than 5 days/ season, while for Cyprus the highest values are not higher than 20 days/season for the same areas. Higher values than MAM are shown for SON with the highest number of days for Sicily and Crete being less than 15 days/season while for Cyprus being about 40 days/season. Regarding the number of very hot days (days with daily maximum temperature $>35^{\circ} \mathrm{C}$, VHD, Fig. S4), the significant values of the index are found in JJA with the highest number of days being about 12 days in eastern Sicily, 5 days in the northwestern Crete and 57 days in central north Cyprus. A much lower number of days are found only in Cyprus in MAM and SON about 2 and 8 days, respectively (not shown). As far as the maximum daily maximum temperatures are concerned (TXx, Fig. S5), which can be seen as an indicator of hot extremes temperature events (Dosio and Fischer 2018), the results indicate a west to east increase for the islands of interest in all seasons except for JJA where Sicily exhibits similar average values to Crete. Overall, the lowest values of the index are shown in DJF, about $18,19.5$ and $21^{\circ} \mathrm{C}$ for Sicily, Crete and Cyprus, respectively, while in JJA, the values reach $34.5^{\circ} \mathrm{C}$ for Sicily and Crete and about $37^{\circ} \mathrm{C}$ for Cyprus.

The average daily minimum temperatures (TN) follow a similar spatial pattern to the one shown for TX over the three islands as far as the highest and lowest values of the index are concerned (Fig. S6). The lowest average values are evident in DJF reaching about $6{ }^{\circ} \mathrm{C}$ in Sicily and Cyprus and $7{ }^{\circ} \mathrm{C}$ in Crete, while the highest evident in JJA reach about 18, 19 and $20^{\circ} \mathrm{C}$ in Sicily, Crete and Cyprus, respectively. Regarding the number of days with daily minimum temperatures $<13^{\circ} \mathrm{C}$ (Fig. S7), the highest values of the index, as expected, are found in DJF with similar average values over the three islands of about 90 days/season. Lower average values are evident for MAM (SON) about 70 (35) days/season for Crete and Cyprus and about 80 (40) days/season in Sicily. It should be mentioned that the number of days in the lower elevation areas are lower than the maximum number of days found in the mountainous areas of the islands by about 10 20 days/season and 40 to 50 days/season in MAM and SON, respectively. In JJA, the highest number of days is shown in the mountainous areas of the three islands. By using a lower temperature threshold, i.e. $8{ }^{\circ} \mathrm{C}$, the highest number of days is confined in DJF and MAM seasons over the three islands (Fig. S8). The average values in DJF reach about 65 days/season in Sicily and Cyprus and 55 in Crete, while in MAM, the average values are lower than DJF by about 30 days in Sicily and Crete and 40 days/season in Cyprus. In SON, the highest values of the indices are confined in the mountainous areas, while in JJA no such days exist over the three islands (not shown). As far as the number of days with daily minimum temperatures $>$ $20{ }^{\circ} \mathrm{C}$ (TR) is concerned (Fig. S9), the highest average number of days is evident in JJA reaching about 24, 36 and 46 days/ season in Sicily, Crete and Cyprus, respectively. The highest values of the index are simulated in the southern coastal areas of Sicily; the northwestern, southern and northeastern coastal areas of Crete; and the northern and northeastern areas of Cyprus. A much lower number of days are simulated in SON over the three islands, whereas a maximum value of about 2 days/season is simulated only for Cyprus in MAM (not shown). The simulations indicate that for the average maximum daily minimum temperatures (TNx), the values of the index in Sicily range from about 12 to $23.5^{\circ} \mathrm{C}$ in DJF and JJA, respectively, in Crete from 13 to $23.5^{\circ} \mathrm{C}$ and in Cyprus from 12 to $24.5{ }^{\circ} \mathrm{C}$ for the same seasons, respectively (Fig. S10).

In Fig. 3, the seasonal total precipitation (RR) is shown for the three islands, while for the rest of the precipitation indices, the results are shown in the Supplementary information. The highest amount of precipitation is simulated in DJF reaching, on average, about 170, 270 and $215 \mathrm{~mm}$ in Sicily, Crete and Cyprus, respectively. Lower values are simulated for MAM and SON, while the lowest values are simulated in JJA in the range of $10-15 \mathrm{~mm} / \mathrm{season}$. Regarding the number of rain days (RR1, Fig. S11), in DJF, about one month/season is simulated on average over the thee islands, while in MAM and SON, the averaged values do not exceed 15 and 17 days/ season, respectively. Averaged simulated heavy precipitation days (days with precipitation $>10 \mathrm{~mm}, \mathrm{RX10}$ ) do not exceed 10 days/season with the highest values being evident in DJF (Fig. S12). In MAM, the averaged values of the index are about 2-3 days/season, while in SON, the values reach 35 days/season. In JJA, the highest values are lower than 2 days/season and are mostly confined in the mountainous areas of the islands. Finally, regarding the average maximum daily precipitation (RX1-day), the highest average values of about $20-30 \mathrm{~mm} / \mathrm{season}$ are simulated in DJF and SON depending on the island. In MAM, lower values than DJF and SON are simulated, about 15-22 days/season, while in summer, the average values are less than 8 days/season (Fig. S13).

\section{Changes in the mean climate}

In Fig. 4, the results of the ensemble mean changes between the near future (2031-2060) and the reference period (1971-2000) under both RCP scenarios (RCP4.5 and RCP8.5) are shown for the seasonal TX. The results indicate robust increases for the total number of grid points covering the three islands. In particular, under RCP4.5 for Sicily and Crete, the highest (lowest) average increases are projected for JJA (MAM) reaching about $1.9^{\circ} \mathrm{C}(\sim$ 
$1.2{ }^{\circ} \mathrm{C}$ and $1.5{ }^{\circ} \mathrm{C}$ for the two islands, respectively) for both islands, while for Cyprus in all seasons, the increase is about 1.6-1.7 ${ }^{\circ} \mathrm{C}$. Under RCP8.5, for Crete and Cyprus, spatially averaged changes higher than $2{ }^{\circ} \mathrm{C}$ are calculated for all seasons with the highest reaching about $2.5^{\circ} \mathrm{C}$ in JJA for Crete and about $2.2{ }^{\circ} \mathrm{C}$ in MAM and SON for Cyprus. For Sicily, the highest simulated increase of about $2.1^{\circ} \mathrm{C}$ is projected for the JJA season, while for the rest of the seasons, the increase is about $1.6-1.7^{\circ} \mathrm{C}$. The areas that are most heavily impacted by the TX increases are the southern coastal areas of Sicily; the northwestern, southern and northeastern coastal areas of Crete; and the northern and northeastern areas of Cyprus.

RR [DJF 1971-2000]
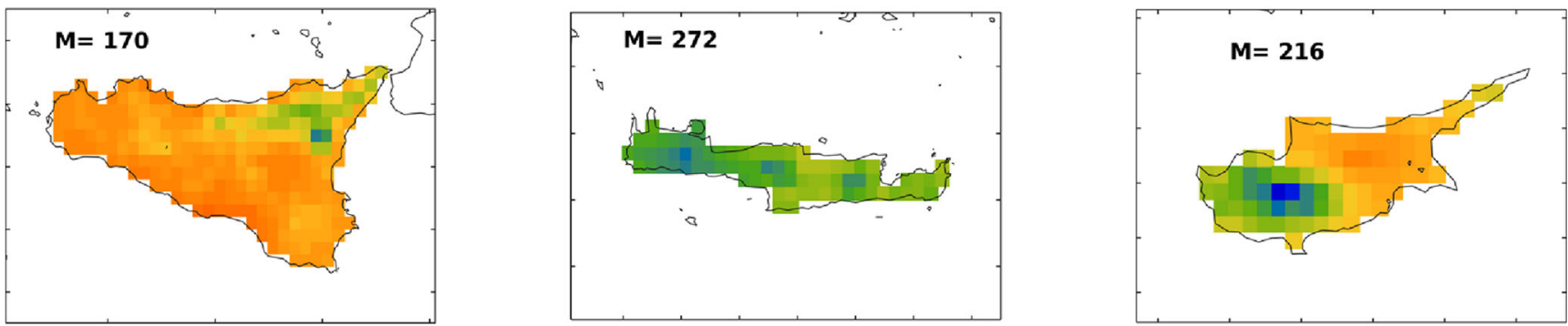

\section{RR [MAM 1971-2000]}
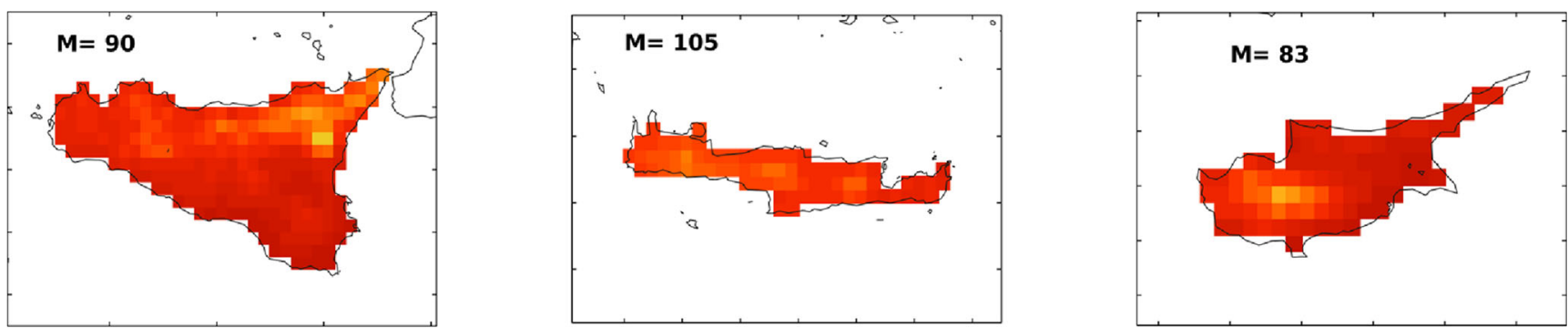

\section{RR [JJA 1971-2000]}
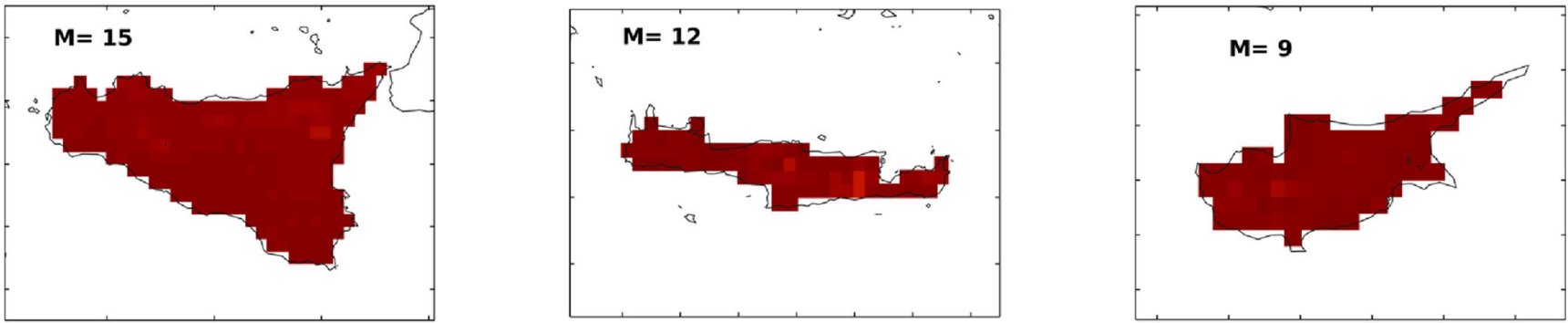

\section{RR [SON 1971-2000]}
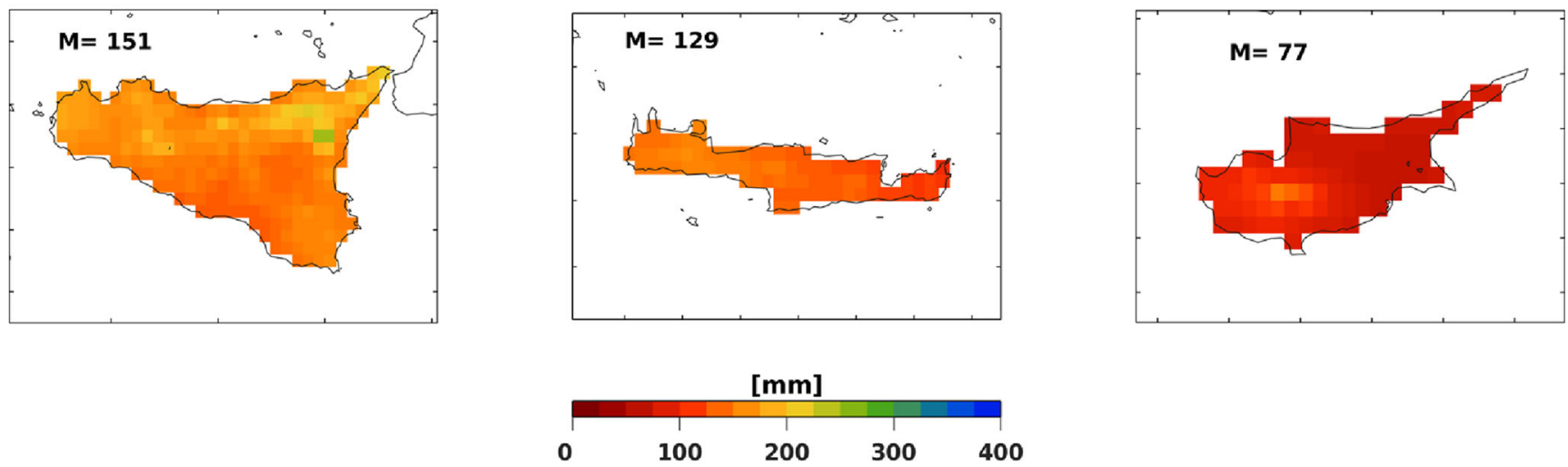

Fig. 3 Mean seasonal total precipitation (RR) for the five-member model sub-ensemble and the period 1971-2000. In each panel, M denotes the spatial average over the grid points covering each island. Units are the same as in the colourbar 

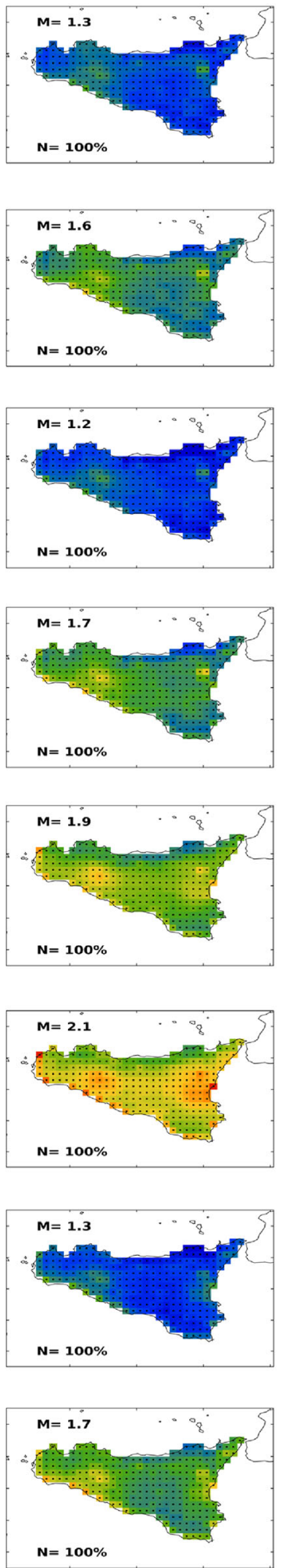

TX [DJF RCP4.5]
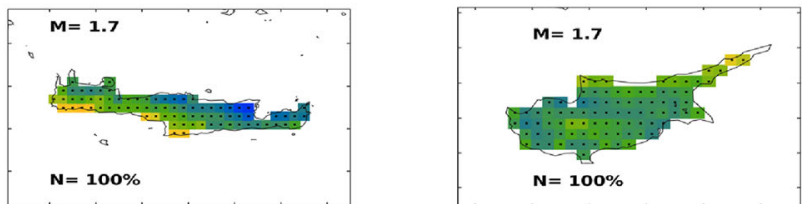

\section{TX [DJF RCP8.5]}
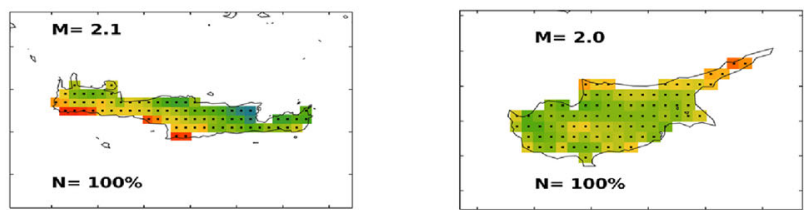

\section{TX [MAM RCP4.5]}
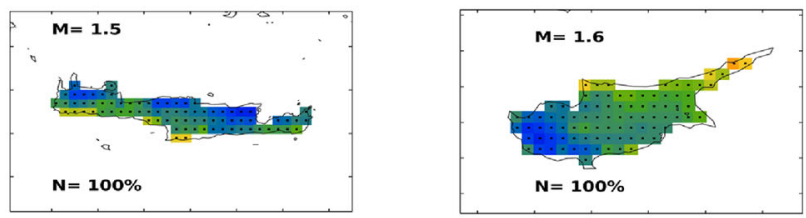

\section{TX [MAM RCP8.5]}
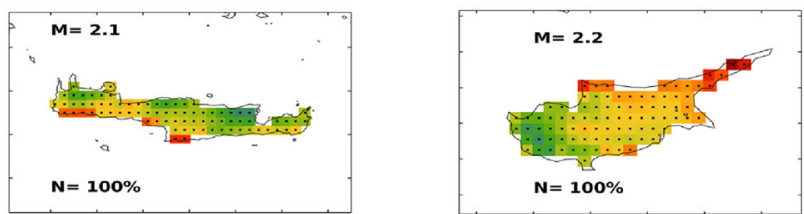

TX [JJA RCP4.5]
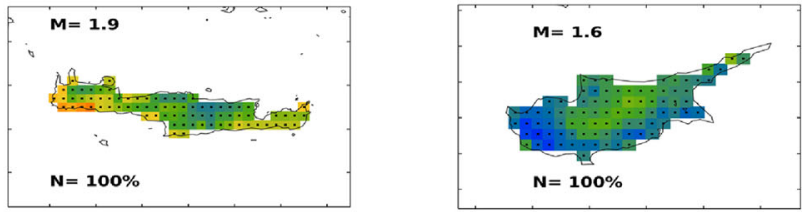

TX [JJA RCP8.5]
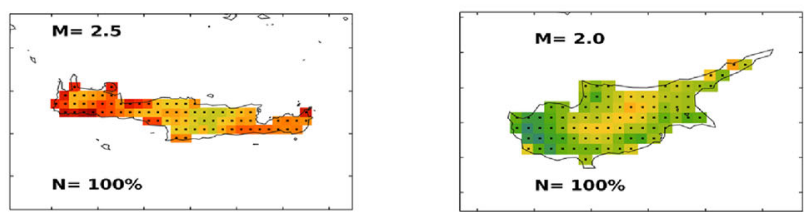

TX [SON RCP4.5]
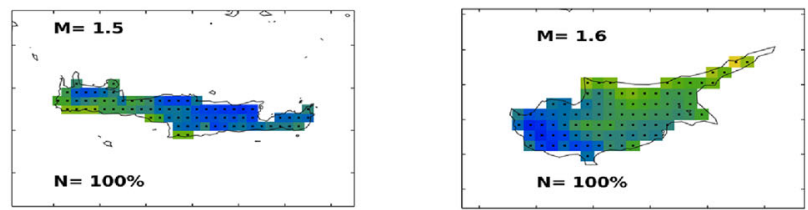

\section{TX [SON RCP8.5]}
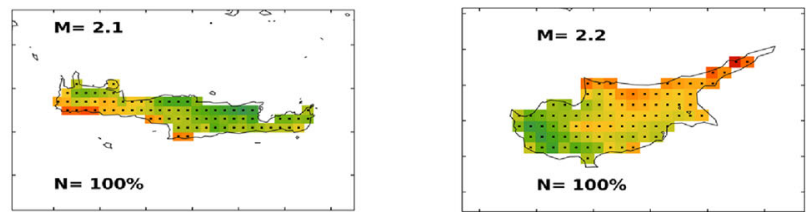

$\left[{ }^{\circ} \mathrm{C}\right]$

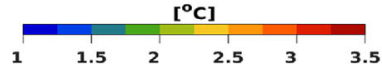

Fig. 4 Mean seasonal absolute changes in the daily maximum temperatures (TX) for the five-member model sub-ensemble between the near future (2031-2060) and the reference period (1971-2000) under both RCP scenarios (RCP4.5 and RCP8.5). In each panel, M denotes the spatial average change over all the grid points covering each island with the units being the same as in the colourbar. Black dots indicate a robust change at the grid point scale, while $\mathrm{N}$ denotes the percentage of grid points where robust changes are found 
Average spatial TN increases higher than $1.2{ }^{\circ} \mathrm{C}$ are found over the three islands for both RCPs (Fig 5). The increases in Sicily range from about $1.2{ }^{\circ} \mathrm{C}$ (MAM) to $1.9{ }^{\circ} \mathrm{C}$ (JJA) and from about $1.5{ }^{\circ} \mathrm{C}$ (DJF) to $2.2{ }^{\circ} \mathrm{C}$ (JJA) under RCP4.5 and RCP8.5, respectively. For the island of Crete, the highest TN increases of about $1.8^{\circ} \mathrm{C}$ and $2.2{ }^{\circ} \mathrm{C}$ under RCP4.5 and RCP8.5 are calculated in JJA, while the lowest are about $1.3^{\circ} \mathrm{C}(\mathrm{MAM})$ and $1.7^{\circ} \mathrm{C}$ (DJF) for the same scenarios, respectively. As far as Cyprus is concerned, the increases under RCP4.5 range from $1.5^{\circ} \mathrm{C}$ (DJF) to $1.6^{\circ} \mathrm{C}$ (MAM and JJA) and from $1.9^{\circ} \mathrm{C}$ (DJF) to $2.2{ }^{\circ} \mathrm{C}(\mathrm{SON})$ under RCP8.5. The areas that are most heavily impacted by the TN increases are the western areas of Sicily; the northwestern, northern and northeastern coastal areas of Crete and the northern; and northeastern areas of Cyprus.

Regarding the precipitaions seasonal chnages, non significant changes are calculated for all seasons and under both scenarios, over the three islands due to the non-statistically significant changes calculated for at least three of the five RCMs (Fig 6).

\section{Changes in the extremes}

The seasonal increases shown in the previous section for both the daily maximum and minimum temperatures are accompanied by increases in the rest of temperature examined indices. In particular, from Fig. S14, it is evident that an increase is projected for the SU index over the three islands for the MAM, JJA and SON periods, with the highest increases for Sicily and Crete shown in JJA (10 to 12 extra days/season) and SON (7 to 13 extra days/season) depending on the scenario. Similar increases in magnitude are evident for Cyprus with the highest increases projected in MAM and SON with robust changes covering the whole island. It should be mentioned that the highest JJA increases are projected for the areas with fewer than 80 days/season during the control period. For the HD index (Fig. S15), the highest increases of 11 (Cyprus RCP4.5) to 24 days/season (Crete RCP8.5) are shown for JJA. Lower increases are also shown for MAM (1-2 days/season in Sicily and Crete and 6-8 days/season in Cyprus) and SON periods (34 and 1-2 days/season in Sicily and Crete, respectively, and 69 days/season in Cyprus) with the highest increases calculated under RCP8.5. The highest increases for the VHD index (Fig. S16) are shown in JJA, 56 extra days/season for Sicily, 5-8 extra days/season for Crete and 15-19 extra days for Cyprus, under RCP4.5 and RCP8.5, respectively. Regarding TXx significant increases are calculated over the three islands under both scenarios. The spatial pattern of the warming over the three islands follow the one of the average daily maximum temperatures with the simulations indicating the highest overall average warming about $4{ }^{\circ} \mathrm{C}$ in Crete (Fig. S17).
Decreases are shown for the $\mathrm{TN}$ indices below a relatively low temperature threshold over the three islands due to the increases in the seasonal TN. More specifically, for the number of days $\mathrm{TN}<13{ }^{\circ} \mathrm{C}$ (Fig. 7), the highest decreases are shown for MAM and SON, ranging from 9 (Sicily RCP4.5) to 16 (Cyprus RCP 8.5) fewer days/season and from about 10 (all three islands under RCP4.5) to about 14 less days/season (all three islands under RCP8.5), for MAM and SON respectively, while for the number of days $\mathrm{TN}<8^{\circ} \mathrm{C}$, the highest decreases are shown for DJF and MAM ranging from 13 (Sicily RCP4.5) to 21 (Cyprus RCP8.5) fewer days/season and from about 9 (all three islands under RCP4.5) to 12 (all three islands under RCP8.5) fewer days/season, respectively (Fig. S18). Regarding the number of tropical nights (TR, Fig. S19), the highest increases are shown over the islands mostly in JJA and SON. The increases over the three islands range from 19 (Cyprus RCP4.5) to 26 (Sicily and Crete under RCP8.5) extra days/season in JJA and from 8 (Sicily and Crete under RCP4.5) to 14 (Cyprus RCP8.5) extra days/ season in SON, with the highest increases in both seasons calculated under RCP8.5 In addition, for Cyprus, an increase of 1-2 extra days/season is shown for the MAM period. As far as TNx is concerned, the increases range from $1.4^{\circ} \mathrm{C}$ (Crete in MAM under RCP4.5) to $2.8^{\circ} \mathrm{C}$ (Sicily and Crete in JJA under RCP8.5) (Fig. S20).

Regarding the precipitation extremes, the results indicate non-significant changes for the majority of the indices following the non-significant seasonal changes over the three islands. However, a few exceptions exist. In particular, in Sicily, robust decreases are projected in the number of rain days (RR1) in MAM under both scenarios by about 3-5 days/ season (Fig. S21). Nevertheless, the percentage of grid points that the changes are found robust is about $9 \%$ and $38 \%$ under RCP4.5 and RCP8.5, respectively. Robust decreases of about 2 days/season are also shown in MAM under RCP8.5 for Crete and Cyprus for a lower percentage of grid points $6 \%$ and 3\%, respectively. For Crete, robust decreases of similar magnitude to the MAM season are simulated in SON under RCP8.5 for a low percentage of grid points $(\sim 9 \%)$ in the central parts of the island. For the heavy precipitation days (RX10), no significant changes are simulated over the three islands for all seasons and under both RCPs (Fig. S22). Finally, for the maximum daily precipitation (RX1-day) robust relative increases of about $20-30 \%$ are shown for Sicily in SON for a low percentage of grid points, less than $10 \%$, for both RCP4.5 and RCP8.5 (Fig. S23).

\section{Comparison with other studies}

The results presented in this study can be compared to the ones from earlier studies mostly in a qualitative way. The reasons behind this statement are related to the different methodologies used: (1) The majority of the most recent studies 

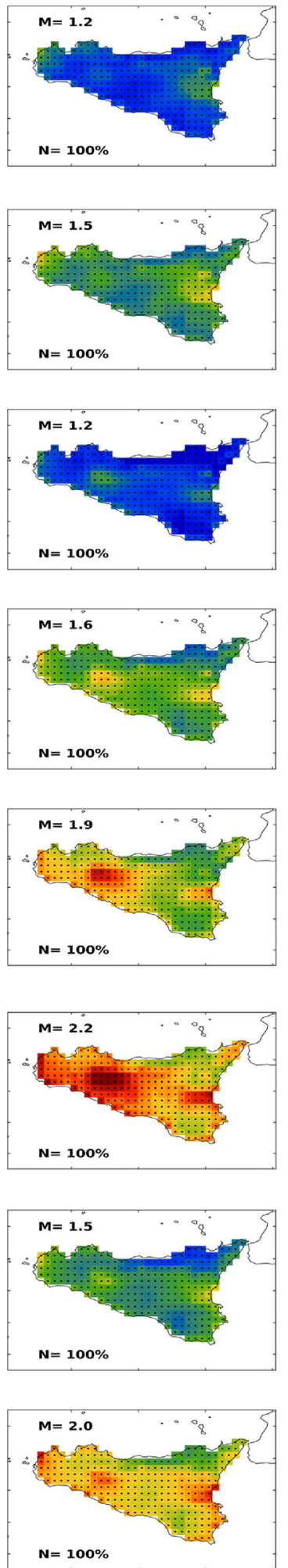

TN [DJF RCP4.5]
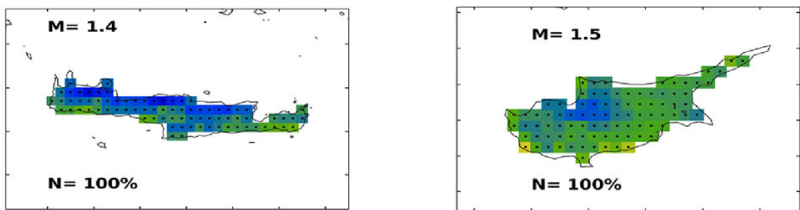

\section{TN [DJF RCP8.5]}
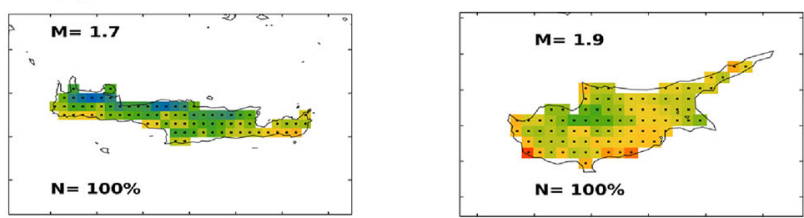

TN [MAM RCP4.5]
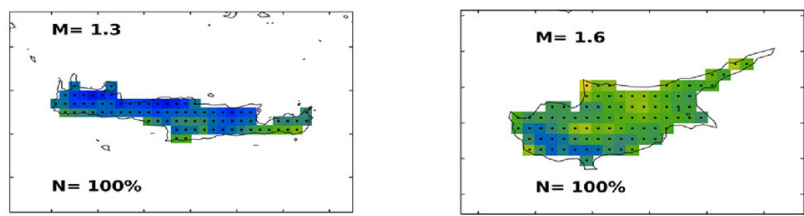

TN [MAM RCP8.5]
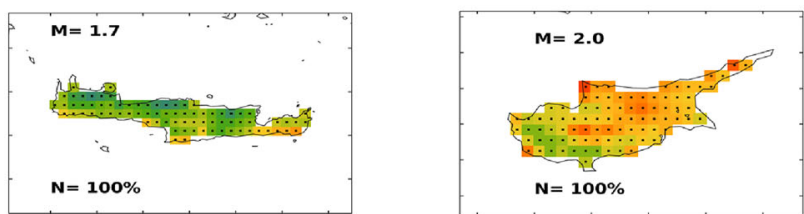

TN [JJA RCP4.5]
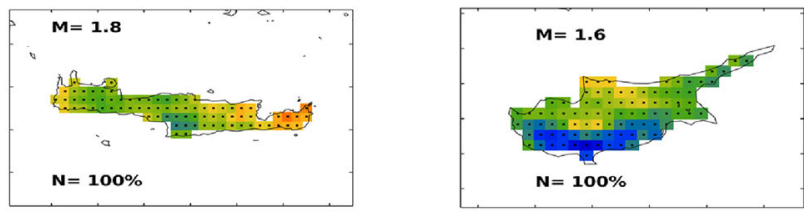

TN [JJA RCP8.5]
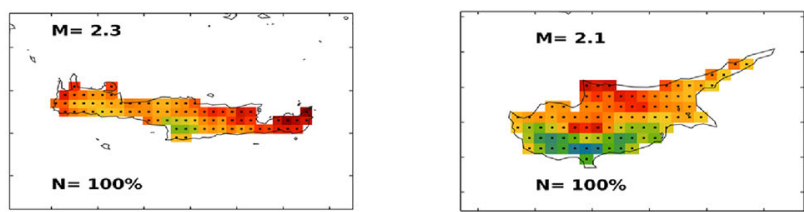

\section{TN [SON RCP4.5]}
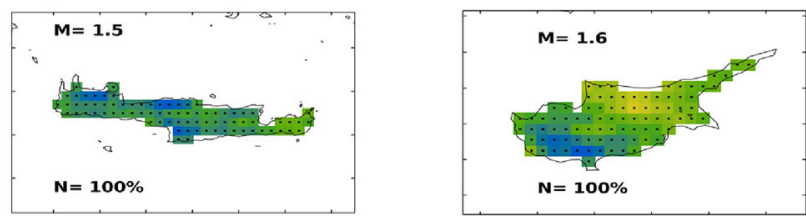

\section{TN [SON RCP8.5]}
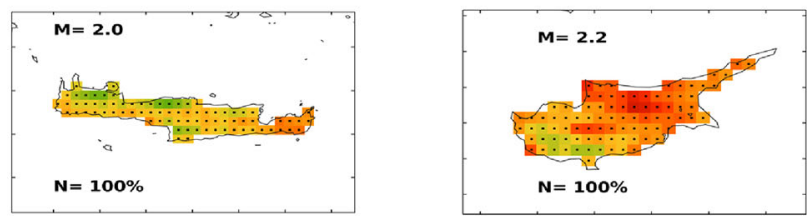

Fig. 5 Mean seasonal absolute changes in the daily minimum temperatures (TN) for the five-member model sub-ensemble between the near future (2031-2060) and the reference period (1971-2000) under both RCP scenarios (RCP4.5 and RCP8.5). In each panel, M denotes the spatial average change over all the grid points covering each island with the units being the same as in the colourbar. Black dots indicate a robust change at the grid point scale, while $\mathrm{N}$ denotes the percentage of grid points where robust changes are found 
using the EURO-CORDEX use the time sampling approach (James et al. 2017), i.e. analysing the climate change signal from simulations at the time global temperature is found to exceed $1^{\circ}, 2^{\circ}$ or $3^{\circ}$ instead of using specific future periods (e.g. Vautard et al. 2014; Dosio and Fischer 2018; Zittis et al. 2019), while the ones that exist in the literature using fixed future periods focus at the end of the century (Jacob et al. 2014; Dosio 2016); (2) the majority of recent studies have used RCMs with a horizontal resolution of about $25 \mathrm{~km}$ with the models' future simulations forced by the older SRES emission scenarios (e.g. Zanis et al. 2009; Giannakopoulos et al. 2011; Hadjinicolaou et al. 2011; Kostopoulou et al. 2014; Zittis et al. 2016); and (3) the reference period differs among the studies, with the earlier studies using as reference period the period 1961-2000 (most of the studies in the previous category), later studies the period 1971-2000 (Jacob et al. 2014; Vautard et al. 2014), while a few studies use the period 1981-2010 (Dosio 2016; Dosio and Fischer 2018; Zittis et al. 2020). However, despite the methodological differences between the studies and the actual changes in magnitude of temperature and precipitation mean climate and extremes, common and similar to this study, conclusions can be extracted. Primarily, the warming in the area is high and robust with a relatively strong increase in the warm extremes, and secondly, less robust or even no significant are the results for precipitation. Regarding the latter, Hadjinicolaou et al. (2011) examining the climate change impacts over Cyprus with the use of an ensemble of six RCMS from the ENSEMBLES project (horizontal resolution about $25 \mathrm{~km}$ ) between the 2026 and 2050 (under A1B) and the 1976-2000 periods found no statistically significant changes in the majority of the precipitation indices examined. Similar results are also found in this study as well as in other recent studies (Dosio and Fischer 2018; Zittis et al. 2019). On the contrary, Zittis et al. (2020) performing simulations with the WRF model, optimized over Cyprus, reported a decrease in the annual total precipitation of about $10-15 \%$ between the 2031 and 2060 period (under RCP8.5) and the 1981 and 2000 period, an increase of about 5 to 10 days in the annual consecutive dry days and a decrease of about 10 days in the number of rain days. However, as stated in their study, the simulations performed were found to be in the dry end of the EURO-CORDEX ensemble.

\section{Implications for the agricultural sector of the islands}

In this section, the impacts of the robust projected increases of temperature means and extremes as well as possible changes in precipitation on the crops of potatoes, olives, wheat, barley, tomatoes and grapes which are the main cultivars of the three islands are discussed. Regarding the first crop, the potato plant is characterized by specific temperature requirements and develops best at about $15-20^{\circ} \mathrm{C}$. A recent study examining the impact of increased day and night temperatures, higher than $35 \mathrm{oC}$ and $25^{\circ} \mathrm{C}$ respectively, during the summer (growing) season found that for temperatures above $20^{\circ} \mathrm{C}$, potato productivity is reduced and the earlier the heating occurs, the more negative is the impact on the growth and total yield of the crop (Rykaczewska 2015). Combined with the results presented in the previous section about VHD and TR in JJA, as well as the indices extension to MAM and SON, it is plausible that the specific crop may be negatively affected from the warming projected over the three islands.

For the olive tree, the impact of a warming climate is more complex. The decreases in the number of days with $\mathrm{TN}<8^{\circ} \mathrm{C}$ and $\mathrm{TN}<13{ }^{\circ} \mathrm{C}$ in DJF and MAM may have a positive effect on trunk growth and the vegetative state and fruit growth respectively, while the increased $\mathrm{TX}$ and $\mathrm{TN}$ temperatures in MAM may lengthen the growing season (Pérez-López et al. 2008; López-Bernal et al. 2020). However, the increase of HD during MAM and JJA (anthesis and veraison period) may affect negatively the fruit set (Moriondo et al. 2019; LópezBernal et al. 2018) and fruit size (Benlloch-González et al. 2019). Moreover, the decreases in the number of chilling days (days with $8^{\circ} \mathrm{C}>\mathrm{TN}>0{ }^{\circ} \mathrm{C}$ ) in DJF may have a negative impact on flowering bud differentiation that requires a period of low temperatures for its completion (Ozdemir 2016; Brito et al. 2019). In addition, the increase in SU in JJA and SON period may produce favourable conditions for increased olive fly infestations, which reduces final yield and quality (Ponti et al. 2014). Finally, the warming projected in this study may have an impact on the quality of the olive oil since it is one of its quality drivers (Ozdemir 2016).

For extreme events occurring at anthesis, cardinal temperatures that may reduce the final yield generally coincide for the considered crops (MAM period). For wheat, higher temperatures at anthesis have been demonstrated to have a detrimental effect on floret fertility and therefore on yield (Porter and Gawith 1999), which onsets when daily maximum temperatures exceed to $30{ }^{\circ} \mathrm{C}$. For barley, though a few documents report the relevant cardinal temperatures, $30{ }^{\circ} \mathrm{C}$ may be still retained as the temperature threshold for optimal fruit set according to Oshino et al. (2011), who reports that maximum temperatures above $30{ }^{\circ} \mathrm{C}$ arrest cell division in anthers leading to a poor pollen germination and therefore lower final yield. Daily temperature above $30{ }^{\circ} \mathrm{C}$ at anthesis have also a negative impact on final yield of tomato, inducing abortion and abscission of developing floral buds (Warner and Erwin 2001). For grapes, Leolini et al. (2018) found that for optimal fruit set, the temperature at anthesis should be limited in a range between 25 and $30^{\circ} \mathrm{C}$, while for temperature, exceeding these thresholds fruit set progressively decreases.

Finally, the impact of climate change on crop yield depends on the combination of warmer temperatures, reduced rainfall 
RR [D]F RCP4.5]
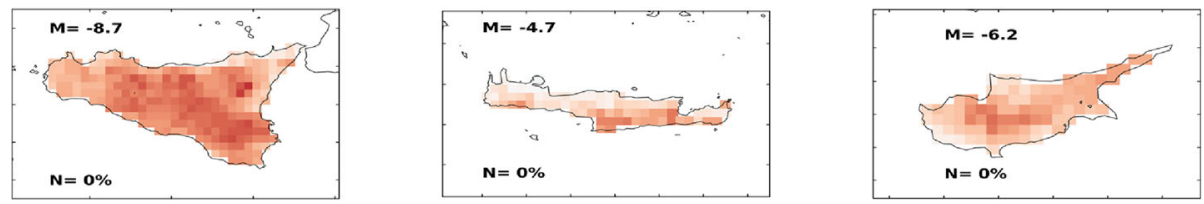

RR [D]F RCP8.5]
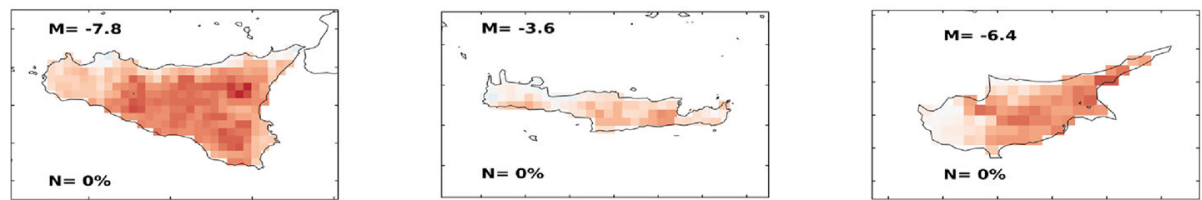

RR [MAM RCP4.5]
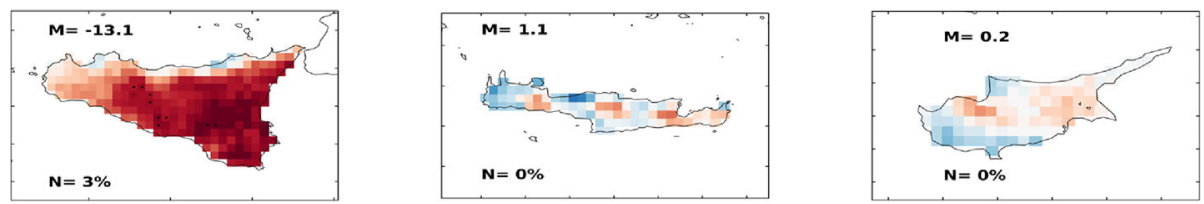

\section{RR [MAM RCPB.5]}
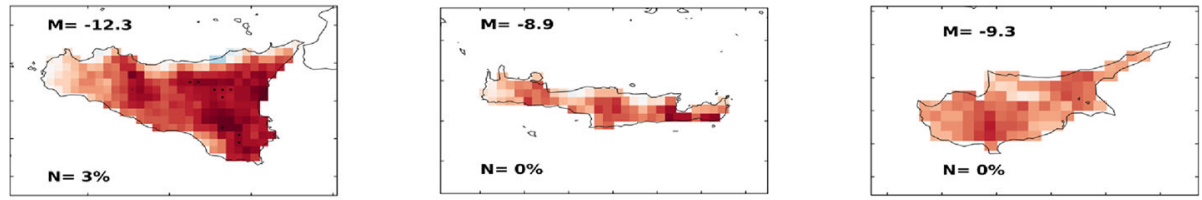

RR [SON RCP4.5]
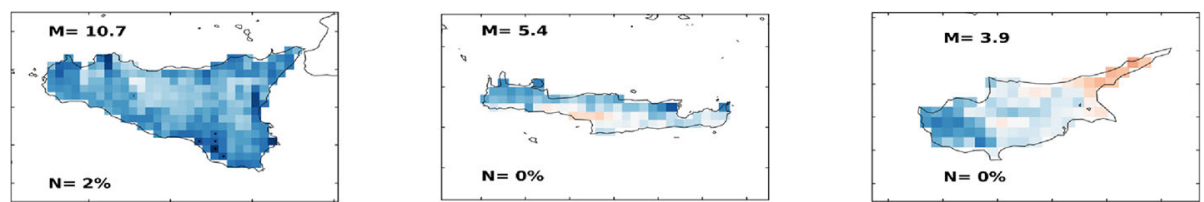

RR [SON RCP8.5]
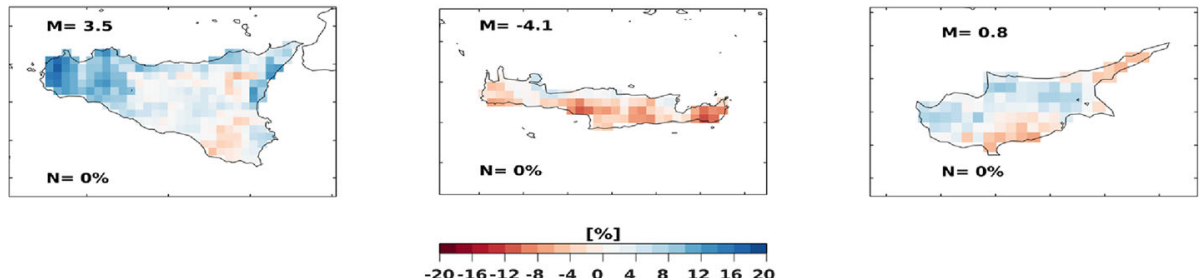

RR [JJA RCP4.5]
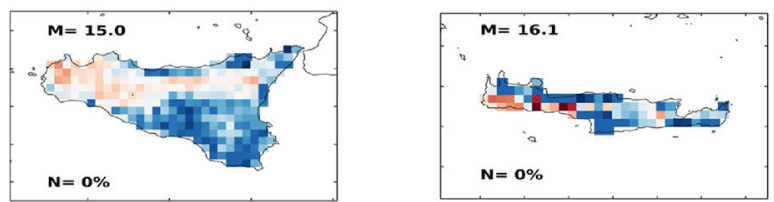

\section{RR [JJA RCP8.5]}
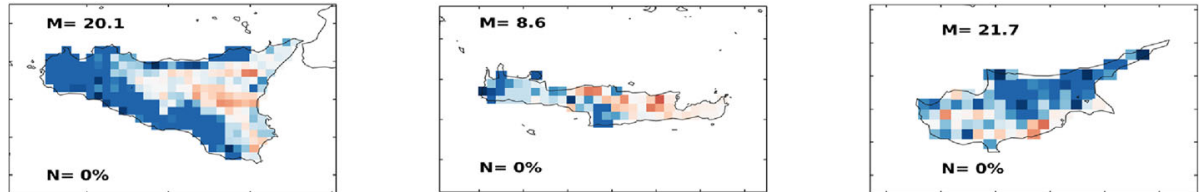

[\%]

$-50-40-30-20-1001020304050$

Fig. 6 Mean seasonal relative changes in total precipitation (RR) between the near future (2031-2060) and the reference period (1971-2000) under both RCP scenarios (RCP4.5 and RCP8.5). In each panel, M denotes the spatial average change over all the grid points covering each island with the units being the same as in the colourbar. Black dots indicate a robust change at the grid point scale, while $\mathrm{N}$ denotes the percentage of grid points where robust changes are found 

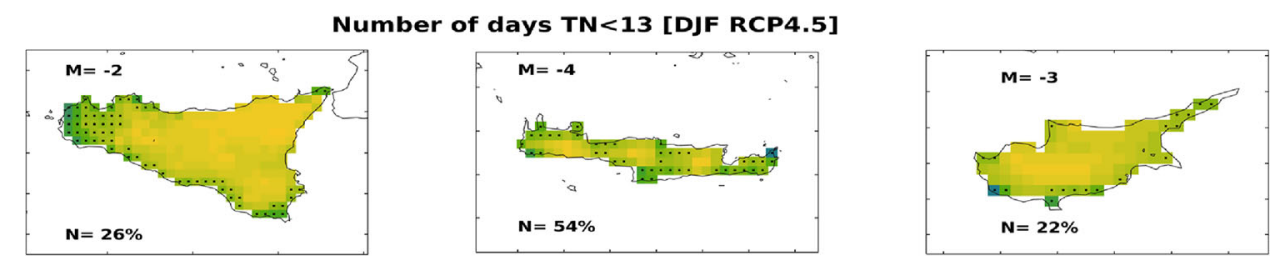

Number of days TN $<13$ [D]F RCP8.5]
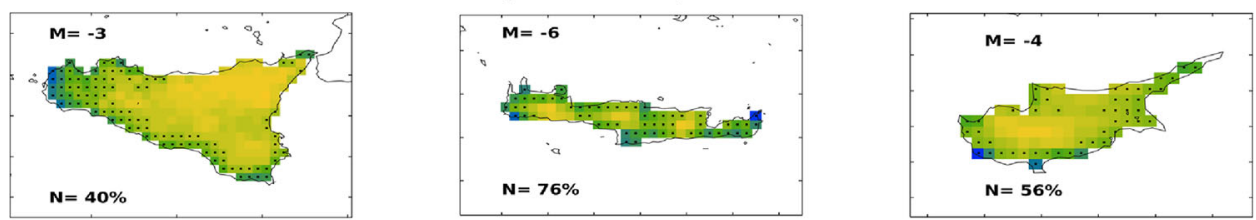

Number of days TN $<13$ [MAM RCP4.5]
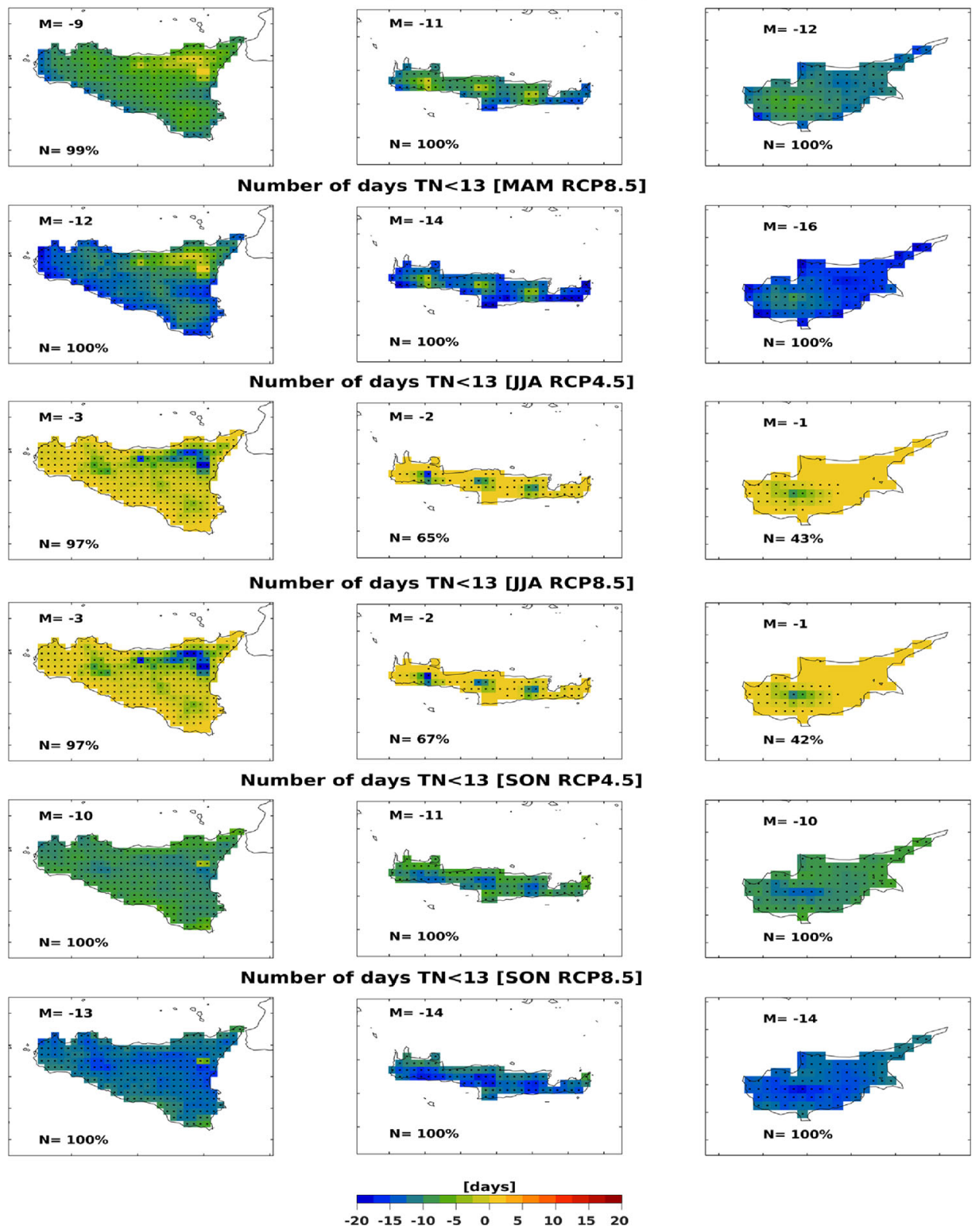

Fig. 7 Mean seasonal absolute changes in the number of days with daily minimum temperatures lower than $13{ }^{\circ} \mathrm{C}$ for the five-member sub-ensemble between the future (2031-2060) and the reference period (19712000) under both RCP scenarios (RCP4.5 and RCP8.5). In each panel,
$\mathrm{M}$ denotes the spatial average change over all the grid points covering each island with the units being the same as in the colourbar. Black dots indicate a robust change at the grid point scale, while $\mathrm{N}$ denotes the percentage of grid points where robust changes are found 
rates and the growing season of the considered crop. When considering the Mediterranean region as a whole, increasing temperatures coupled with the limited rainfall amounts simulated for the future generally follow a seasonal trend. The highest increases of temperature are observed in summer period, while these effects are less pronounced in autumn and spring, whereas for rainfall, a mixed pattern with nonsignificant changes is simulated. As a matter of fact, summer crops such as tomato, grapevine and olive tree whose growing cycle covers spring and summer period are more exposed to the impact of climate change with respect to winter crops, such as barley and wheat whose growing cycle takes place during a favourable period (Moriondo et al. 2011; Webber et al. 2018). The impact of such a change on crop yield is especially due to the combined effect of warmer temperatures, which increase the evapotranspirative demand of the crops and the reduction of available water that prevents this demand from being fully satisfied. Changes in dry and wet spell, though not robust in our results, may play an additional role in worsening or reducing the impact of climate change on crops. In the last years, western Mediterranean experienced a low reduction in total yearly accumulated rainfall with respect to the baseline (Kostopoulou and Jones 2005), and this was associated to an increase in dry spell implying an increase in extreme rainfall events and that not all rain becomes water available to plants. This trend, if projected for the future period, will further increase the impact of climate change on crops.

\section{Summary}

In this study, the impact of climate change on both the mean climate and the extremes over the islands of Sicily, Crete and Cyprus using a sub-set of bias-adjusted EURO-CORDEX simulations for the 2031-2060 future period under two RCP scenarios, namely, RCP4.5 and RCP8.5, was examined. The analysis revealed robust increasing changes between the period 2031 and 2060 and the reference period for both the mean maximum and minimum temperatures on a seasonal basis, as well as for the temperature related extremes examined under both different scenarios. On the contrary, the changes in the total precipitation were found less pronounced under both the RCP4.5 and RCP8.5 compared to the reference period. In addition, a qualitative assessment of the projected warming was made based on literature for the main crops cultivated in the three islands. The analysis revealed that the projected warming mostly in spring and summer might expose the crops to conditions likely to have an adverse impact on the phenological stages of the plants which, as a consequence, may affect the plants' production and crop quality.

Uncertainties related to this study are mostly associated to the projections of future climate themselves where despite the scientific effort, the overall uncertainty has not been significantly reduced (Qian et al. 2016). It should be noted that the quality of the observational dataset used to biasadjust the models output affects the quality of the biascorrected data. However, E-OBS is constantly improving (Cornes et al. 2018) and is considered a state-of-the-art gridded interpolated product for the European domain, which despite its uncertainties (Kotlarski et al. 2014 and references therein) has been broadly used in many studies (e.g. Dosio 2016; Dosio and Fischer 2018; Varotsos et al. 2019). It should also be mentioned that for a quantitative assessment of the climate change impact on the different crops cultivated in the three islands, the high-resolution bias-adjusted simulations could be used as input to drive crop model simulations that describe the biophysical interactions between climate and the agricultural systems.

Despite the uncertainties related to this study, the methodology and results obtained here can be used as part of a climate change risk and vulnerability assessment that can contribute to the development of an adaptation strategy on the three islands or in a more localized level. This could be done not only in the agricultural sector as presented in the current study but also in other sectors, such as human health and tourism. Given the results presented in this study regarding the projected changes in temperature for Sicily, Crete and Cyprus are of the same magnitude or higher than the projected changes shown in earlier studies for the central and northwestern Europe, under RCP4.5, for the end of the century (Jacob et al. 2014), the characterization "hot spots for climate change" in Europe can be supported.

Supplementary Information The online version contains supplementary material available at https://doi.org/10.1007/s10113-020-01736-0.

Acknowledgements We acknowledge the E-OBS dataset from the EUFP6 project UERRA (http://www.uerra.eu) and the Copernicus Climate Change Service and the data providers in the ECA\&D project (https:// www.ecad.eu). The EURO-CORDEX data used in this work were obtained from the Earth System Grid Federation server (https://esgf-data. dkrz.de/projects/esgf-dkrz/).We are grateful to all the modelling groups that performed the simulations and made their data available, namely, Laboratoire des Sciences du Climat et de l'Environnement (IPSL), the Max Planck Institute (MPI), the Royal Netherlands Meteorological Institute (KNMI), the Rossby Centre and Swedish Meteorological and Hydrological Institute (SMHI).

Funding The authors acknowledge co-finance from the EC LIFE programme LIFE ADAPT2CLIMA (LIFE14 CCA/GR/000928) "Adaptation to Climate change Impacts on the Mediterranean islands' Agriculture".

\section{Compliance with ethical standards}

Conflict of interest The authors declare that they have no conflict of interest.

Open Access This article is licensed under a Creative Commons Attribution 4.0 International License, which permits use, sharing, 
adaptation, distribution and reproduction in any medium or format, as long as you give appropriate credit to the original author(s) and the source, provide a link to the Creative Commons licence, and indicate if changes were made. The images or other third party material in this article are included in the article's Creative Commons licence, unless indicated otherwise in a credit line to the material. If material is not included in the article's Creative Commons licence and your intended use is not permitted by statutory regulation or exceeds the permitted use, you will need to obtain permission directly from the copyright holder. To view a copy of this licence, visit http://creativecommons.org/licenses/by/4.0/.

\section{References}

Bartók B, Tobin I, Vautard R, Vrac M, Jin X et al (2019) A climate projection dataset tailored for the European energy sector Climate Serv 16:100138 https://doi.org/10.1016/j.cliser.2019.100138

Benlloch-González M, Sánchez-Lucas R, Bejaoui MA, Benlloch M, Fernández-Escobar R (2019) Global warming effects on yield and fruit maturation of olive trees growing under field conditions. Sci Hortic 249:162-167. https://doi.org/10.1016/j.scienta.2019.01.046

Brito C, Dinis L-T, Moutinho-Pereira J, Correia CM (2019) Drought stress effects and olive tree acclimation under a changing climate. Plants (Basel) 8:232. https://doi.org/10.3390/plants8070232

Cannarozzo M, Noto LV, Viola F (2006) Spatial distribution of rainfall trends in Sicily (1921-2000). Phys Chem Earth A/B/C 31:12011211. https://doi.org/10.1016/j.pce.2006.03.022

Casanueva A, Herrera S, Iturbide M, Lange S, Jury M et al (2020a) Testing bias adjustment methods for regional climate change applications under observational uncertainty and resolution mismatch. Atmos Sci Lett 21:e978. https://doi.org/10.1002/asl.978

Casanueva A, Kotlarski S, Fischer AM, Flouris AD, Kjellstrom T et al (2020b) Escalating environmental summer heat exposure - a future threat for the European workforce. Reg Environ Chang 20:40. https://doi.org/10.1007/s10113-020-01625-6

Cornes RC, van der Schrier G, van den Besselaar EJM, Jones PD (2018) An ensemble version of the E-OBS temperature and precipitation data sets. J Geophys Res Atmos 123:9391-9409. https://doi.org/10. 1029/2017jd028200

Cramer W, Guiot J, Fader M, Garrabou J, Gattuso J-P et al (2018) Climate change and interconnected risks to sustainable development in the Mediterranean. Nat Clim Chang 8:972-980. https://doi.org/ 10.1038/s41558-018-0299-2

Dosio A (2016) Projections of climate change indices of temperature and precipitation from an ensemble of bias- adjusted high-resolution EURO-CORDEX regional climate models. J Geophys Res Atmos 121:5488-5511. https://doi.org/10.1002/2015jd024411

Dosio A, Fischer EM (2018) Will half a degree make a difference? Robust projections of indices of mean and extreme climate in Europe under $1.5^{\circ} \mathrm{C}, 2^{\circ} \mathrm{C}$, and $3{ }^{\circ} \mathrm{C}$. Global Warming Geophys Res Lett 45:935-944. https://doi.org/10.1002/2017gl076222

Founda D, Varotsos KV, Pierros F, Giannakopoulos C (2019) Observed and projected shifts in hot extremes' season in the Eastern Mediterranean. Glob Planet Chang 175:190-200. https://doi.org/ 10.1016/j.gloplacha.2019.02.012

Giannakopoulos C, Kostopoulou E, Varotsos KV, Tziotziou K, Plitharas A (2011) An integrated assessment of climate change impacts for Greece in the near future. Reg Environ Chang 11:829-843. https:// doi.org/10.1007/s10113-011-0219-8

Giorgi F (2006) Climate change hot-spots. Geophys Res Lett:33. https:// doi.org/10.1029/2006g1025734

Hadjinicolaou P, Giannakopoulos C, Zerefos C, Lange MA, Pashiardis S et al (2011) Mid-21st century climate and weather extremes in
Cyprus as projected by six regional climate models. Reg Environ Chang 11:441-457. https://doi.org/10.1007/s10113-010-0153-1

Iturbide M, Bedia J, Herrera S, Baño-Medina J, Fernández J et al (2019) The R-based climate4R open framework for reproducible climate data access and post- processing. Environ Model Softw 111:42-54. https://doi.org/10.1016/j.envsoft.2018.09.009

Jacob D, Petersen J, Eggert B, Alias A, Christensen OB et al (2014) EURO-CORDEX: new high-resolution climate change projections for European impact research. Reg Environ Chang 14:563-578. https://doi.org/10.1007/s10113-013-0499-2

James R, Washington R, Schleussner C-F, Rogelj J, Conway D (2017) Characterizing half-a-degree difference: a review of methods for identifying regional climate responses to global warming targets WIREs. Climate Change 8:e457. https://doi.org/10.1002/wcc.457

Kostopoulou E, Jones PD (2005) Assessment of climate extremes in the Eastern Mediterranean. Meteorog Atmos Phys 89:69-85. https:// doi.org/10.1007/s00703-005-0122-2

Kostopoulou E, Giannakopoulos C, Hatzaki M, Karali A, Hadjinicolaou $\mathrm{P}$ et al (2014) Spatio- temporal patterns of recent and future climate extremes in the eastern Mediterranean and Middle East region. Nat Hazards Earth Syst Sci 14:1565-1577. https://doi.org/10.5194/ nhess-14-1565-2014

Kotlarski S, Keuler K, Christensen OB, Colette A, Déqué M et al (2014) Regional climate modeling on European scales: a joint standard evaluation of the EURO-CORDEX RCM ensemble. Geosci Model Dev 7:1297-1333. https://doi.org/10.5194/gmd-7-12972014

Leolini L, Moriondo M, Fila G, Costafreda-Aumedes S, Ferrise R et al (2018) Late spring frost impacts on future grapevine distribution in Europe. Field Crop Res 222:197-208. https://doi.org/10.1016/j.fcr. 2017.11.018

Lionello P, Scarascia L (2018) The relation between climate change in the Mediterranean region and global warming. Reg Environ Chang 18: 1481-1493. https://doi.org/10.1007/s10113-018-1290-1

López-Bernal Á, Morales A, García-Tejera O, Testi L, Orgaz F et al (2018) OliveCan: a process-based model of development, growth and yield of olive orchards. Front Plant Sci 9. https://doi.org/10. 3389/fpls.2018.00632

López-Bernal Á, García-Tejera O, Testi L, Orgaz F, Villalobos FJ (2020) Studying and modelling winter dormancy in olive trees. Agric For Meteorol 280:107776. https://doi.org/10.1016/j.agrformet.2019. 107776

Moriondo M, Giannakopoulos C, Bindi M (2011) Climate change impact assessment: the role of climate extremes in crop yield simulation. Clim Chang 104:679-701. https://doi.org/10.1007/s10584-0109871-0

Moriondo M, Leolini L, Brilli L, Dibari C, Tognetti R et al (2019) A simple model simulating development and growth of an olive grove. Eur J Agron 105:129-145. https://doi.org/10.1016/j.eja.2019.02. 002

Moss RH, Edmonds JA, Hibbard KA, Manning MR, Rose SK et al (2010) The next generation of scenarios for climate change research and assessment. Nature 463:747-756. https://doi.org/10.1038/ nature 08823

Oshino T, Miura S, Kikuchi S, Hamada K, Yano K et al (2011) Auxin depletion in barley plants under high-temperature conditions represses DNA proliferation in organelles and nuclei via transcriptional alterations plant. Cell Environ 34:284-290. https://doi.org/10. $1111 / \mathrm{j} .1365-3040.2010 .02242 . \mathrm{x}$

Ozdemir Y (2016) Effects of climate change on olive cultivation and table olive and olive oil quality. Scientific papers. Series B, horticulture, volume LX, Print ISSN 2285-5653, 65-70

Pérez-López D, Ribas F, Moriana A, Rapoport HF, De Juan A (2008) Influence of temperature on the growth and development of olive (Olea europaea L.) trees. J Hortic Sci Biotechnol 83:171-176. https://doi.org/10.1080/14620316.2008.11512366 
Philandras CM, Nastos PT, Kapsomenakis J, Douvis KC, Tselioudis G et al (2011) Long term precipitation trends and variability within the Mediterranean region. Nat Hazards Earth Syst Sci 11:3235-3250. https://doi.org/10.5194/nhess-11-3235-2011

Ponti L, Gutierrez AP, Ruti PM, Dell'Aquila A (2014) Fine-scale ecological and economic assessment of climate change on olive in the Mediterranean Basin reveals winners and losers. Proc Natl Acad Sci 111:5598-5603. https://doi.org/10.1073/pnas.1314437111

Porter JR, Gawith M (1999) Temperatures and the growth and development of wheat: a review. Eur J Agron 10:23-36. https://doi.org/10. 1016/S1161-0301(98)00047-1

Qian Y, Jackson C, Giorgi F, Booth B, Duan Q et al (2016) Uncertainty quantification in climate Modeling and Projection. Bull Am Meteorol Soc 97:821-824. https://doi.org/10.1175/bams-d-1500297.1

Rykaczewska K (2015) The effect of high temperature occurring in subsequent stages of plant development on potato yield and tuber physiological defects. Am J Potato Res 92:339-349. https://doi.org/10. 1007/s12230-015-9436-x

van Vuuren DP, Edmonds J, Kainuma M, Riahi K, Thomson A et al (2011) The representative concentration pathways: an overview. Clim Chang 109:5. https://doi.org/10.1007/s10584-011-0148-z

Varotsos KV, Giannakopoulos C, Tombrou M (2019) Ozonetemperature relationship during the 2003 and 2014 heatwaves in Europe. Reg Environ Chang 19:1653-1665. https://doi.org/10. 1007/s10113-019-01498-4

Varouchakis EA, Corzo GA, Karatzas GP, Kotsopoulou A (2018) Spatiotemporal analysis of annual rainfall in Crete, Greece. Acta Geophys 66:319-328. https://doi.org/10.1007/s11600-018-0128-z

Vautard R, Gobiet A, Jacob D, Belda M, Colette A et al (2013) The simulation of European heat waves from an ensemble of regional climate models within the EURO-CORDEX project. Clim Dyn 41: 2555-2575. https://doi.org/10.1007/s00382-013-1714-z

Vautard R, Gobiet A, Sobolowski S, Kjellström E, Stegehuis A et al (2014) The European climate under a $2{ }^{\circ} \mathrm{C}$ global warming.
Environ Res Lett 9:034006. https://doi.org/10.1088/1748-9326/9/ 3/034006

Viola F, Liuzzo L, Noto LV, Lo Conti F, La Loggia G (2014) Spatial distribution of temperature trends in Sicily. Int J Climatol 34:1-17. https://doi.org/10.1002/joc.3657

Warner RM, Erwin JE (2001) Effect of high-temperature stress on flower number per inflorescence of 11 Lycopersicon esculentum mill. Genotypes Hortsci 36:508 (abstract)

Webber H, Ewert F, Olesen JE, Müller C, Fronzek S et al (2018) Diverging importance of drought stress for maize and winter wheat in Europe. Nat Commun 9:4249. https://doi.org/10.1038/s41467018-06525-2

Zanis P, Kapsomenakis I, Philandras C, Douvis K, Nikolakis D et al (2009) Analysis of an ensemble of present day and future regional climate simulations for Greece. Int J Climatol 29:1614-1633. https://doi.org/10.1002/joc.1809

Zhang X, Alexander L, Hegerl GC, Jones P, Tank AK et al (2011) Indices for monitoring changes in extremes based on daily temperature and precipitation data WIREs. Climate Change 2:851-870. https://doi. org/10.1002/wcc. 147

Zittis G, Hadjinicolaou P, Fnais M, Lelieveld J (2016) Projected changes in heat wave characteristics in the eastern Mediterranean and the Middle East. Reg Environ Chang 16:1863-1876. https://doi.org/ 10.1007/s10113-014-0753-2

Zittis G, Hadjinicolaou P, Klangidou M, Proestos Y, Lelieveld J (2019) A multi-model, multi-scenario, and multi- domain analysis of regional climate projections for the Mediterranean. Reg Environ Chang. https://doi.org/10.1007/s10113-019-01565-w

Zittis G, Bruggeman A, Camera C (2020) 21st century projections of extreme precipitation indicators for Cyprus. Atmosphere 11:343. https://doi.org/10.3390/atmos11040343

Publisher's note Springer Nature remains neutral with regard to jurisdictional claims in published maps and institutional affiliations. 